\title{
Leveraging Design Thinking for Pharmaceutical Digital Marketing
}

\author{
Anothai Ngamvichaikit \\ School of Management Science, Sukhothai Thammathirat Open University, \\ Nonthaburi, Thailand
}

\begin{abstract}
Worldwide, the time spent online and in digital media has been increasing, thus becoming the primary source of health and medical information. This phenomenon is driving all business, including the pharmaceutical industry, in gearing toward digital marketing strategies. Developing countries like Thailand still extend existing laws to regulate digital media despite the differences with traditional media, and consumers face the risks of buying drugs illegally and products that overclaim despite stringent pre-approval regulations on drug marketing. This study utilizes design thinking as a human-centric research method to propose appropriate and practical digital marketing guidelines for the pharmaceutical industry, using 53 informants. The problems were that consumers face persuasive risks and the need for reliable sources of drug information. The current regulatory process places a high burden on regulators and the laws that enforce it. However, several new digital strategies such as unbranded information and targeted marketing are not covered by existing laws. Regulations on teleconsultation are also needed, but no legislation currently exists for such activities. And finally, experts have articulated four domains as follows: eRegulations, e-Information sources, and e-Consultation to provide easy access to professionals, and e-Ethics, a supportive mechanism toward ethical drug marketing.
\end{abstract}

Keywords: Design Thinking; Pharmaceutical Business; Digital Marketing; Information Seeking; Humanistic Marketing; Thai Regulatory. 


\section{Introduction}

Digital devices allow for the free movement of vast amounts of information in the shortest time possible between people in different parts of the world. The Thai FDA is like most developing countries in that it prohibits providing drug information directly to consumers. Only self-medicating drug groups can advertise with a pre-marketing approval process. FDA Advertising regulations have extended since 1967 from mass traditional media to the ubiquitous digital media with limited manpower. In reality however, consumers can search for the needed information on any drug, including prescription drugs, for their decision making. If the marketing regulatory controls were effectively enforced, online drug overclaims would no longer be an issue. In today situation, government are facing misconduct on digital communication which could result in incurred criminal challenges (Homhuan, 2013). The multiple directions of this misconduct are not only related to domestic violations but also related to the global reach of internet technologies.

Digital consumers are seeking health information through digital communication and use for their health decision. The health information seeking in the digital consumer and professionals push pharmaceutical businesses, to prioritize going online despite there is no appropriate, clearcut guideline for their digital practices (Parekh, Kapupara \& Shah, 2016; Lad, Muragundi \& Ligade, 2017). Pharmaceutical marketing is positioned controversially and delicately between business effectiveness and ethics. Drug communication must convey scientific evidence and drug efficacy, bundling in the risks as well. In most developing countries, drug information for brand names is not allowed to be advertised directly to consumer except for the household drugs. Whereas what and how information that drug companies can provide still lack ethical, spelledout guidelines, especially in developing countries like Thailand, where consumers are perceived as children, needing protection from a flood of harmful or persuasive drug information provided by non-benevolent parties or consumers themselves which flourish and grow unchecked in digital media. Anyone can discuss drug information freely with an unknown person with no guarantee that there's no hidden, commercial agenda.

Medicine comprises ethical products which are dispensed for professional reasons that concern many levels of factors, such as patient, economic, and social, reasonable usage, and so on. Therefore, the pharmaceutical business, to be humanistic, cannot trigger a drug purchase based on consumer demand. Unlike other businesses, pharmaceutical marketing is burdened with controlled regulation and substantial controversy over their efforts to influence physician prescription and consumer purchase. Digital marketing can unleash the opportunity to interact with consumers and provide one-sided information without disclosing identity or sufficient regulatory monitoring. The relationship between pharmaceutical marketers (agents) and the Thai FDA (principal) are aligned with the agency theory. These roles depend on a pharmaceutical to provide faithful information to consumers which contradicts their financial motivation. Government regulators have a duty to protect consumer by monitoring agents for exaggerated advertising claims and illegal drug sales, and they still have no proper mechanism.

Nowadays, consumers who need digital information sources for drug advice face unapproved advertising content and indigenous tactics and need to be persuaded to 
resist buying drugs from unethical marketing operators. This complex dilemma leads to the research objective of providing the appropriate pharmaceutical marketing framework for digital media. The research focuses on balanced health information addressing behavior, ethical concerns of government and business opportunities of pharmaceuticals. A digital marketing framework for humanistic products like medicines is needed to shape informative that is not persuasive marketing. The theoretical contribution of the humanistic marketing concept and agency theory are applied.

Design thinking was successfully implemented in business innovations, among other examples in the academic literature which include healthcare and its creative, collaborative and practical values as shown in such empirical studies (Ferreira, Song, Gomes, Garcia \& Ferreira, 2015). According to the research objective, to propose a marketing framework for digital pharmaceutical marketing that satisfies all stakeholders, the study utilizes design thinking as a research method, to provide applicable guidelines for digital pharmaceutical marketing and resolve the discrepancies among regulatory policies, as well as consumer and business behaviors in healthcare markets like Thailand. Although design thinking has been widely successful in managerial applications, the research process of design thinking in this study also contributes to research methodology for academic researchers.

\section{Literature Review}

US empirical evidence shows a rise in digital advertising spending, shifting from traditional media advertising to digital, in Pharmaceutical marketing (Kim, 2015). With flourishing digital communication, Thai consumers spent a long time on digital media, especially social media (ETDA, 2019). A Thai study revealed the problems incurred from drug over-advertising, unauthorized advertising and illegal online selling through digital media (Sirikanratana, 2016; Maimon, 2018).

Consumer behavior is changing toward seeking information through digital media before meeting with a physician. Consumers reported they first use the internet when seeking health information as opposed to traditional media, family and friends, and healthcare professionals, and rely on the information source to select their physician, hospital or even treatment by themselves (Jacobs, Amuta \& Jeon, 2017). Also, healthcare professionals, including physicians, are using smartphones and mobile devices to search for medical information, and most seek drug information from the most authoritative databases, like UpToDate and Medscape (Boruff \& Storie, 2014). Digital drug information is used as reference for both consumer purchases and healthcare professionals for prescribing decisions (Davies, 2007; Fox \& Duggan, 2013). Acquiring drug information online positively influences the self-initiated purchasing of drugs from online channels that are made easy access but not risk free. However, health literacy relied on an individual's existing knowledge, which varies among informationseekers. Thus, there is healthcare research interested especially in how to improve the quality of digital drug information (Lalazaryan \& Zare-Farashbandi, 2014; Tan \& Goonawardene, 2017). The role of a validating mechanism needs to be carefully discussed when a medical commercial plays a major role in the exploitation of consumer's decisions. 
Consumer information-seeking behaviors in a fast-moving, digital information technology age led to an agency problem between information providers (agents) and ethics regulators (principals) from the agency theory (Eisenhardt, 1989). Ethics regulators aim to protect consumers, with the expectation that information providers work in the interests of consumers. Pharmaceutical companies have assumed the role of information providers, but their financial motivation may not be reliable as agents working on behalf of consumers. If the monitoring or incentivizing mechanisms are not designed for digital platforms, fraudulent actions of such agents will be sure to occur. Medicine and healthcare are considered humanistic marketing (Varey \& Pirson, 2013; Borgerson, 2015), so the agency problem of drug information is highly important. With multiple parties involved, the design thinking method is utilized as the research methodology to ideate possible solutions.

\section{Design Thinking}

Many academics have tried to define the concept of design thinking (Buchanan, 1992; Katoppo \& Sudradjat, 2015; Chan, 2018; Hendricks, Conrad, Douglas \& Mutsvangwa, 2018). It can be explained as a designer's sensibility and methods to meet stakeholders needs (Brown, 2008; Dell'Era, Magistretti \& Verganti, 2018), or a human centric process (Lockwood, 2009) to provide problem-solving actions. Design thinking is being used in various practical settings like innovation, software design, critical thinking, etc. Design thinking may result in adaptable, practical and usable solutions for complex problems. Some scholars refer to design thinking as a participatory and "human-oriented" research methodology (Keshavarz \& Maze, 2013). Empirical evidence recommends design thinking to solve challenging social problems like healthcare, which focus on practical validity rather than statistical validity (Buchanan, 1992; Mintrom \& Luetjens, 2016; McGann, Blomkamp \& Lewis, 2018). A systematic review recommends that design thinking methodology with a thorough and structured process in healthcare research has benefits over the traditional method in terms of higher usability (Altman, Huang \& Breland, 2018) based on the theoretical concept of user co-creation (Payne, Storbacka \& Frow, 2008). The benefit of using design thinking to shed light on a pharmaceutical digital marketing model is spelled out, although using design thinking as a complementary research method is still limited, it is advantageous in avoiding research bias and empowers all users to co-create the solutions (Katoppo \& Sudradjat, 2015; Goodman, Schneeweiss \& Baiocchi, 2017).

Despite the design thinking process in the literature using different terminology, the studies support a shared view of the process. Gathering user needs and defining problems are the initial step in exploring the qualitative research. This is followed by idea generation employing a collaborative and creative thinking approach, including prototype and testing experimentation to determine the practicality. Here we use the extended approach by Stanford D. School, suggesting five stages: empathize, define, ideate, prototype and test, in order to provide a thorough research process similar to other healthcare settings (Altman et al., 2018). Healthcare products and policy innovation are wildly accepted to embrace design thinking to create the practical solution (Roberts, Fisher, Trowbridge \& Bent, 2016; Chan, 2018). 


\section{Research Method}

The history of studies and ethics controls in Thailand fall mainly under the Thai FDA, according to drug classifications. The Thai FDA designates drugs into three categories: household medicines, dangerous drugs and specially controlled drugs. Drugs not included in these three categories are automatically grouped in the non-dangerous category (Leelavanich, Adjimatera, Broese Van Groenou \& Anantachoti, 2020; Thailaws.com, n.d.). Thai regulations prohibit pharmaceutical companies from communicating drug information with registered brand names, a so-called "advertisement" or attempt to sell such products online. The exception is for drugs in the household remedies category, which can be advertised after FDA approval to sell online. Regulations in the 1967 Drug Act have been used for more than five decades and have never been amended, even though consumer digital behavior has emerged as a public health agenda over the past 20 years. Although the misconduct of pharmaceutical companies was being increasingly found in digital channels, but decreasingly in traditional channels (Kim, 2015; Limbu, McKinley \& Temperini, 2019).

The Thai FDA has established two departments: The Drug Advertising Control Department, to approve pre-marketing advertising in both online and offline channels but use the same regulations in the 1967 Drug Act, as well as The Complaint and Enforcement Management Center to monitor all misconduct, such as drug overclaims, illegal drug advertising, selling online, and handling consumer complaints (Medicine Regulation Division, n.d.). Based on this assumption, there should not be any drug advertisements in any media without FDA approval. A Thai FDA report states that there were 1,570 violations of health product advertisements and 300 violations of drug advertisements in 2019, which were mostly online overclaims and illegal drug selling (Oyor Digital Library, 2019). In recent research (Maimon, 2018; Kumnooy, 2020) on digital placement, there was illegal drug advertising without permission, overclaimed information related to medicines, and drug selling in the e-marketplace, websites, and social media. Problems of online drug information have today become an important issue and urgently need a legal framework to cope with it.

There are two types of pharmaceutical companies in Thailand. First, multinational companies (MNCs) open Thai subsidiaries to operate globally or regionally. All marketing activities are guided from their international marketing departments, which are adapted locally according to the destination preference and regulations. Certainly, MNCs are aware of the high legal costs of penalties for non-compliance with either the host or destination market (Parekh et al., 2016). The code of conduct is written to reaffirm all sales and marketing implementation accordingly. Second, domestic pharmaceuticals operate only in their home country of Thailand and are mostly familyowned businesses. Their marketing activities are created locally with more relaxed controls compared with MNCs.

Types of marketing strategies are separated into two categories according to regulations: Over the Counter (OTC) and Ethical marketing. Firstly, for drugs to be promoted to end consumers, OTC marketing emphasizes brand name awareness to drive consumers to their local pharmacy outlets. The second group, ethical marketing, covers products that can be promoted only to healthcare professionals using sciencebased information. All materials with brand names need to be submitted for pre- 
approval by the Thai FDA (Leelavanich et al., 2020). Additionally, MNC pharmaceutical companies are required to perform an internal evaluation to ensure compliance prior to government submission.

From the survey, pharmaceutical marketing is focused more on digital communication toward consumers to create brand awareness and convert buying behavior, compared to other industries' digital marketing (Comscore, 2014). Digital marketing of pharmaceuticals comprises social media, search engine optimization, websites, email, application marketing and e-commerce if possible (Parekh et al., 2016). Ethical marketing cannot implement general public digital marketing, as only professionals are allowed to access medical information. However, a new concept of digital marketing recommends providing more information, consumer contact (Memisoglu, 2017), and digital drug information, which influence customer decision-making and shorten their purchase cycle regardless of how complicated the product is, such as medicines (Holtgräfe \& Zentes, 2012; Chiou \& Tucker, 2016). Unbranded communication can publish without any regulatory approval and send marketing messages to consumers, even when the medicines are categorized as ethical products.

From the above background, this study explores multiple perspectives from a user perspective as the first step of design thinking (Brown, 2008). Digital pharmaceutical marketing caters to the tension between what information consumers and healthcare professionals want, the concerns of government regulators and ethical controllers, and what pharmaceutical companies believe to be beneficial. Therefore, multigroup informants who are directly involved with digital pharmaceutical marketing were recruited purposively in order to gather their needs as shown in Table 1.

Table 1: Informant Characteristics

\begin{tabular}{|c|c|c|c|c|}
\hline Stakeholders & $\begin{array}{l}\text { Number of } \\
\text { informants }\end{array}$ & Criteria & Age & $\begin{array}{c}\text { Median Age } \\
\text { (Interquartile } \\
\text { Range) }\end{array}$ \\
\hline $\begin{array}{l}\text { I. Ethical } \\
\text { Controller } \\
\text { Group }\end{array}$ & $\begin{array}{l}4 \text { FDA executives } \\
6 \text { ethics } \\
\text { controllers from } \\
\text { professional } \\
\text { associations and } \\
\text { NGOs }\end{array}$ & $\begin{array}{l}\text { Regulate or provide } \\
\text { digital marketing } \\
\text { guidelines or protect } \\
\text { consumers from } \\
\text { digital pharmaceutical } \\
\text { marketing for over } 1 \\
\text { year. }\end{array}$ & $40-66$ & $\begin{array}{c}55.00 \\
(47.75,57.75)\end{array}$ \\
\hline \multirow[t]{2}{*}{$\begin{array}{l}\text { II. Target } \\
\text { Customer } \\
\text { Group of } \\
\text { Digital } \\
\text { Pharmaceutical } \\
\text { Marketing }\end{array}$} & 20 Consumers & $\begin{array}{l}\text {-Search recent drug } \\
\text { information (within } 1 \\
\text { year) or buy } \\
\text { pharmaceutical } \\
\text { products on digital } \\
\text { platforms. }\end{array}$ & $24-50$ & $\begin{array}{c}38.00 \\
(29.75,41.25)\end{array}$ \\
\hline & $\begin{array}{l}11 \text { health } \\
\text { professionals }\end{array}$ & $\begin{array}{l}\text {-Search recent drug } \\
\text { information (within } 1 \\
\text { year) on digital } \\
\text { platforms. }\end{array}$ & $22-48$ & $\begin{array}{c}38.00 \\
(27.00,46.00)\end{array}$ \\
\hline $\begin{array}{l}\text { III. } \\
\text { Pharmaceutical } \\
\text { Group }\end{array}$ & $\begin{array}{l}10 \text { Pharmaceutical } \\
\text { marketers (5 } \\
\text { MNCs and } 5 \text { local } \\
\text { drug marketers) }\end{array}$ & $\begin{array}{l}\text { Have conducted } \\
\text { digital pharmaceutical } \\
\text { marketing for more } \\
\text { than } 1 \text { year. }\end{array}$ & $29-51$ & $\begin{array}{c}40.50 \\
(36.00,46.25)\end{array}$ \\
\hline
\end{tabular}


According to the previous literature, 30-50 informants are sufficient for capturing heterogeneity (Dworkin, 2012; Malterud, Siersma \& Guassora, 2016). This study exceeds the recommendation by using 53 informants to reach data saturation in all three informant groups. This study followed the 5 steps of the D.School design thinking process (Brown, 2008; Lefebvre \& Kotler, 2011) and the healthcare literature (Ferreira et al., 2015; Altman et al., 2018; Chan, 2018) as shown in Figure 1. First, a qualitative phenomenological interview is used as an approach for the empathy step (Ratcliffe, 2012). Second, the content analysis defines the underlying problems in the define step. Third, expert brainstorming ideates the proposed solutions. Fourth, a solution prototype is developed. Fifth, acceptability of the prototype is tested with the information groups in the empathy step. The research process complies with the standards of the Human Ethics Committee, Sukhothai Thammathirat Open University, which were approved in November 2019 (IRB-SHS-2019/1004/63).

Figure 1: Design Thinking Process

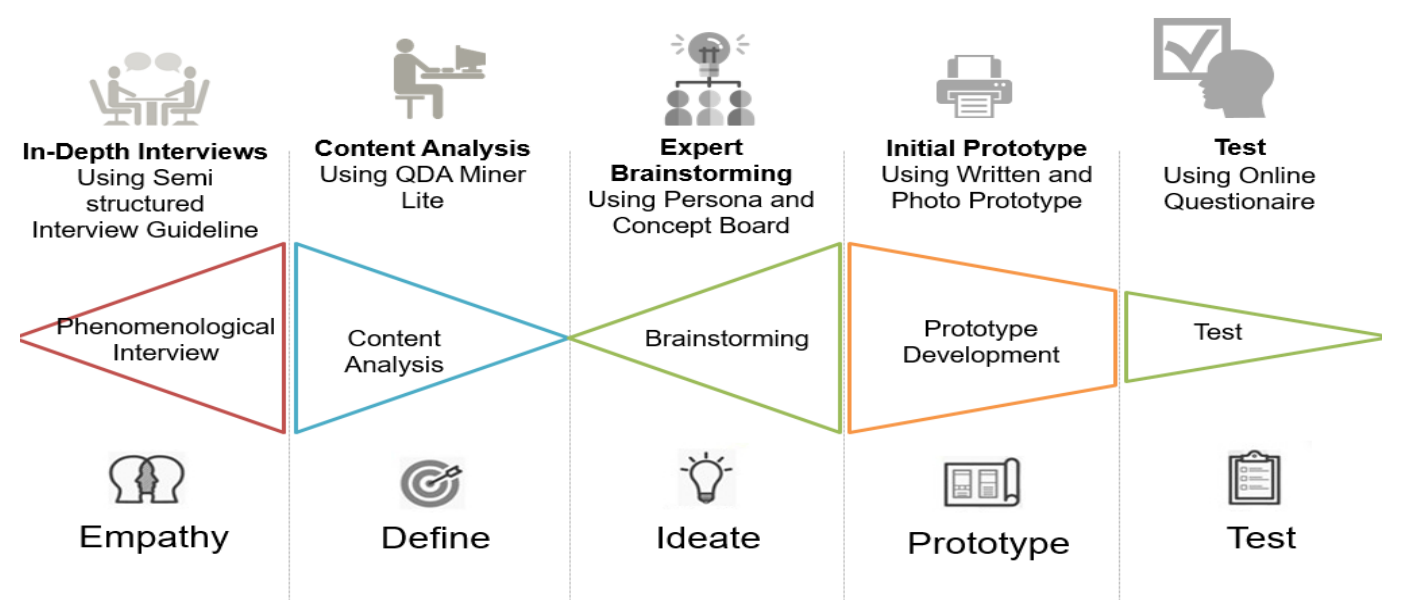

\section{Empathy}

The researcher reviewed the relevant documents and digital media and developed a semi-structured interview guideline, which passed validation from the experts toward exploring stakeholder problems. A research brief was introduced and consented to by the research informants. The researcher asks about their experience in digital pharmaceutical marketing and navigates to their incurred problems in accordance with the phenomenological inquiry of qualitative research (Creswell \& Poth, 2016). Additional probing questions are added during data collection if the meaning is unclear. To go beneath the surface, the researcher observed the surrounding environment and digital media that informants mentioned to anticipate the explicit and latent problems of informants.

\section{Define}

The researcher carried out transcription of the audio records and sent them to individual informants for validation. After their approval, each transcript was read again thoroughly and was analyzed thematically with QDA Miner Lite including open coding and categorizing as shown in table II. For example, one ethics controller mentioned 
“...It is a gray zone, we want to regulate it, but it's not addressed in existing law ..." The sentence was coded as 'complicated work from current regulation' to control digital marketing.

Table 2: Category and Code

\begin{tabular}{|c|c|c|}
\hline Category & Code & Frequency of cases \\
\hline Digital drug & - Reliable & 17 of 20 consumers \\
\hline information source & $\begin{array}{l}\text { - Non-biased } \\
\text { - Complete information } \\
\text { - Easily understandable information }\end{array}$ & $\begin{array}{l}6 \text { of } 10 \text { Healthcare } \\
\text { professionals }\end{array}$ \\
\hline Teleconsultation & $\begin{array}{l}\text { - Need digital channel to access health } \\
\text { consultation. } \\
\text { - Concern over consumer risk from } \\
\text { biased information and illegal online } \\
\text { pharmacies }\end{array}$ & $\begin{array}{l}11 \text { of } 20 \text { consumers } \\
7 \text { of } 10 \text { Healthcare } \\
\text { professionals }\end{array}$ \\
\hline $\begin{array}{l}\text { High burden from } \\
\text { existing regulation }\end{array}$ & $\begin{array}{l}\text { - High amount of work } \\
\text { - Complicated work under existing law } \\
\text { - Risk of being sued } \\
\text { - Long time to accomplish (law } \\
\text { enforcement for regulators / } \\
\text { promotional approval for marketers) }\end{array}$ & $\begin{array}{l}9 \text { of } 12 \text { ethic controller } \\
\text { group } \\
6 \text { of } 10 \text { pharmaceutical } \\
\text { marketer group }\end{array}$ \\
\hline $\begin{array}{l}\text { Pharmaceutical } \\
\text { Marketino }\end{array}$ & - Concern over compromised & 6 from 12 ethic \\
\hline $\begin{array}{l}\text { Effectiveness vs. } \\
\text { Ethics }\end{array}$ & $\begin{array}{l}\text { - Concern over the risk of unethical } \\
\text { operations from pharmaceuticals }\end{array}$ & 6 from 10 marketers \\
\hline
\end{tabular}

In addition to defining problems, the researcher developed representative persons (Persona) with unknown identities in order to prompt the experts toward having an indepth understanding and be ready to ideate the solutions in a later step (Miaskiewicz \& Kozar, 2011; So \& Joo, 2017).

Figure 2: Example of informant's persona

\begin{tabular}{|c|c|c|}
\hline Persona & $\begin{array}{l}\text { Story Telling } \\
\text { A } 48 \text { year old woman who likes to talk } \\
\text { consult friends about her health. She prefer } \\
\text { to buy online medicine both international and } \\
\text { domestic shops including prescription drugh. } \\
\text { Although she know that there is no } \\
\text { government credential in Thailand. } \\
\text { Graduated with a Ph.D. in America for over } \\
20 \text { years. }\end{array}$ & $\begin{array}{l}\text { Vision } \\
\text { In fact, the } \\
\text { government work } \\
\text { has to come down } \\
\text { to monitor and } \\
\text { inspect, give the } \\
\text { certificate to the } \\
\text { seller. Buyers will } \\
\text { receive both } \\
\text { convenience and } \\
\text { security. }\end{array}$ \\
\hline \multirow{2}{*}{$\begin{array}{l}\text { Personal Challenges } \\
\text { How to get detailed } \\
\text { drug information and } \\
\text { buy online medicine } \\
\text { for safety and } \\
\text { convenient use? }\end{array}$} & $\begin{array}{l}\text { Problem } \\
\text { Want complete and compare drug } \\
\text { information, or al least the drug leaflet. }\end{array}$ & \multirow{2}{*}{$\begin{array}{l}\text { Impact } \\
\text { Time and Safety } \\
\text { I spend time a lot to } \\
\text { find out information } \\
\text { and I have bought } \\
\text { medicine without } \\
\text { any government } \\
\text { control of standard. }\end{array}$} \\
\hline & $\begin{array}{l}\text { Management } \\
\text { I have ever searched my symtoms by } \\
\text { visiting the MD website to get the list of } \\
\text { drugs and then take them to google, look for } \\
\text { properties and list of brands, prices and then } \\
\text { continue to buy. My regular websites are } \\
\text { Amazon or I Lazada that } I \text { feel trust }\end{array}$ & \\
\hline
\end{tabular}




\section{Ideate}

The researcher conducted a full day brainstorming session with five digital marketing experts who understood the design thinking process and digital marketing business. Firstly, the researcher presented the current situation, personas and problems to enable experts to find solutions to their problems. The researcher triggered the brainstorming with an open-ended question, "What can we do to enable (the informant) to reduce/solve the existing (problem)?", and let each expert suggest possible solutions to the digital marketing issues of the business.

\section{Prototype}

The researcher collected the conclusions from the Concept Board and created the digital marketing guidelines for the pharmaceutical industry into a prototype. The prototypes of the design thinking is developed in a written statement with a picture of so called minimum viable products (MVPs), which is defined as a product with just enough tangible features to test with early users (Dell'Era, Magistretti, Cautela, Verganti \& Zurlo, 2020).

\section{Test}

To solicit feedback on the prototypes (Becker, Park, Boustani \& Chorpita, 2019), the MVPs evaluation form was sent to test the MVPs in the original sample group and feedback was received from 50 of 53 informants. After each MVP consideration, the acceptability test measured their agreement using a five-point Likert scale ("totally disagree" toward totally agree") and open-ended questions that asked for suggestions on what could be improved in each prototype item of the pharmaceutical industry in Thailand (e.g., What do you suggest for a proposed policy about consumer drug information?). The metric analysis of mean and variation was conducted with scalemeasured questions and a verbatim record of the feedback in open ended questions was used to improve the initial prototypes.

\section{Results}

The qualitative data analysis supports the main problems of informants related with digital pharmaceutical marketing as follows:

\section{Current regulations are highly burdened, intricately and emotionally}

Constantly changing digital technology places an extra burden on regulators. The Drug Act of 1967 governs traditional marketing, with no statements specifically written for digital pharmaceutical marketing. Regulators extend the coverage toward digital marketing, with decisions placed under government official consideration.

Advertising regulations governing upstream premarketing restricts certain content and depends on the time-consuming practice of submitting requests for approval. Approved content is the result of interpretation of the law by officials in regard to whether content is exaggerated or not. Section 88(1) states that the advertising of drugs is not a claim of a definite cure or prevention of a disease, while the working principle of FDA officers 
is to apply the laws in supervising pharmaceutical marketing. FDA officers therefore rely on interpretation of the traditional 1967 law for overseeing digital pharmaceutical marketing. Digital marketing can lead consumers toward sales funnels that are a latent advertisement without brand presentation.

"...If you only communicate with the company name without the drug name, you do not need to ask for permission. It is a gray zone, we want to regulate it, but there is no statement in existing law ...” (FDA Regulator RS02)

\section{Digital drug information sources are needed, but reliable domestic sources are lacking}

Digital information provides consumers with the means to reduce their health information deficit. There are two occasions of consumer drug information-seeking. First, to participate in their drug decisions with healthcare professionals, some consumers seek digital drug information prior to doctor or pharmacist consultation to reduce uncertainty. Second, they seek drug information during their or their family's medicinal intake. Online drug selling is not approved legally in the country and most Thai consumers still receive medication and get advice from healthcare providers at physical of public healthcare locations. At home, consumers still need to research their drug information by searching digital media, especially administrative methods, contraindications, allergies and possible interactions with other medicines.

"The online drug information is useful. We don't have to ask a lot at the pharmacy. Finding information about drugs online helps to understand and decide before purchase...." (Consumer CS19)

Without proper controls on drug information, sometimes providing drug information leads to convert opportunistically to illegal online drug selling. This example was asserted by FDA executive from their arrest of a famous health website which provided drug information on diseases in Thailand.

"...Consumers perceive the website as providing good information and start to ask if they can buy. For a while, they started to sell medicine like antibiotics, Sidegra (Thai Viagra), dangerous and prescription drugs. . . A corner of the room had a lot of boxes of orders..." (FDA regulators, RS03)

The need of reliable information sources does not only mean fair, complete and balanced information, but also benevolent information without converting to sales. Not only do consumers rely on drug information digitally, but healthcare professionals also search scientific drug information and refer to searching to assist on their patient medication.

"I am the only pharmacist in this community healthcare service...I search every day to provide the medicinal information... I routinely refer to online information..." (Pharmacist, HS02) 


\section{A hope of legitimate online pharmacies with consultation under the supervision of government agencies in the digital age}

Medicine is a complicated chemical product which contains both benefit and adverse effects. Providing complete and balanced drug information from healthcare professionals remains particularly important. While the Thai Public health system does initiate home healthcare for drug use, these services might only suit the elderly who stay at home during the day. It may not be suitable for a wide range of other consumers. Certainly, working consumers are comfortable with digital applications and call for teleconsultation to assist in their health and drug use.

“... Government agencies or healthcare professionals should account for digital drug information to provide online drug selling and consultation with consumers..." (Consumer, CS03)

7 of 20 consumers prefer to purchase online medication, their primary motives being convenience (24/7 availability) and lower price. However, overall consumers encourage government agencies and healthcare professionals to equip online pharmacies with teleconsultation.

Healthcare professionals are unanimous in their concern that consumers should have easy access to digital drug information. Digital propaganda caters to the lowest common denominator among consumers and may adversely affect wrong health decisions like drug abuse. Consumers should be advised by healthcare professionals on their drug usage. Certainly, professional advice needs to be paid for, especially doctors. Teleconsultation may lessen the concerns of healthcare professionals with lower costs to consumers. A platform and regulations need to be developed and legitimized to maintain a standard of care, not profitable channels of crime as are currently the case.

\section{Pharmaceutical marketers feel conflicted between ethics and effectiveness}

The pharmaceutical industry invents medicines for healthier lives and is a partner in the world healthcare ecosystem. Being ethical pharmaceutical marketers in this business requires another skill set. Not only marketing skills, but also an ethical business skill set. The FDA has strictly controlled misconduct by some pharmaceuticals which incurred in the past, sometimes by outright criminals. Different countries or regions hold different regulatory regimes. Multinational pharmaceuticals have high costs to pay for misconduct. However, pharmaceuticals provide codes of conduct to protect the organization from lawsuits. From a subsidiary marketing point of view, the guideline for positioning oneself between regulatory mandates and regulation-free operations remains vague. While the Thai FDA requires branded communication to submit for approval as a prerequisite before publishing, marketers who aim to be effective digitally exploit unregulated and unbranded communication.

"...Every communication toward the healthcare professional needs to be submitted to the FDA, our communications have become difficult to accomplish and the process is terribly slow.... As digital communication is extremely fast paced, we cannot wait. So, we communicate with non-branded information...." (Marketer, MS03) 
Not only to avoid regulatory censorship that undermines effectiveness, unbranded marketing gains, but more consumer trust from third party websites. Displaying fair and balanced drug information may become difficult for the pharmaceutical industry, which competes aggressively to gain market share.

"...Unbranded information can liberate our digital content that was never approved by FDA. The banner can be placed together with the unbranded information. We have to do it because our FDA, unlike other countries, is very rigidly strict... Online has room for us to play 'zig zag' but we don't break the rules..." (Marketer, MS08)

After presenting the problems along with a sample of the Persona, experts ideated a prototype for the digital pharmaceutical marketing approach in four domains, the socalled R-I-C-E approach, as follows.

\section{(i) Platform for 'e-Regulatory' control (R)}

To control digital marketing, we should apply modern regulatory patterns and technology. As per this ethical code of medicine, the guideline for digital pharmaceutical marketing cannot emerge from a business perspective only. Instead, the government guideline needs to be at the frontier of the industry. Regulatory organizations like the Thai FDA need to change to 'e-regulatory', with the qualities of agile, technology driven and cooperative organizations.

Firstly, the current situation is changing quickly, so drug laws should provide more flexibility to change. In the technology area, a regulatory sandbox has been utilized under user cooperation. Agile government must dare to draft, experiment, test and change iteratively to increase their knowledge on regulation. The restricting premarketing controls should be changed to be post-marketing controls. The amount of digital communication is not able to align with premarketing approval. Government officials should change their efforts to navigate unethical activities without bothering with ethical activity.

Secondly, technology can enhance technological enforcement. There are three key technologies to increase the effectiveness of e-regulation.

- Identification technology: Identification helps increase digital communication responsibility and can support digital business in the future, whether it is ecommerce or serves a standard of online consultation.

- Communication technology: Using Chatbot to provide information on medicines on behalf of healthcare professionals for easy questions. This technology can connect to digital consultation if queries are necessary to provide complicated personal advice.

- Early alert technologies against digital misconduct: Prevention is better than late enforcement, so early alert is needed to prevent the negative impact of illegal drug marketing. Using big data technologies and artificial intelligence to investigate marketing crime and uplift work Efficiency for government officials toward more offenses of digital pharmaceutical marketing.

Lastly, quick monitoring of digital marketing communications requires a network of partnership consisting of government agencies, media owners, professional 
associations, social sectors, and pharmaceutical companies. More cooperation provides increasing resource for Thai FDA to handle digital pharmaceutical marketing.

\section{(ii) The development of drug 'e-Information' sources (I)}

Today, digital drug information has become a necessity for consumers and healthcare professionals. Government agencies, academic institutions and pharmaceutical companies should cooperate to become a unified partnership for creating important sources of information, such as disease and drug information, for lay consumers, drug information and updated research for healthcare professionals, etc. Even though information sources are available internationally, there is a need for reliable domestic information incorporated with a reimbursement list and FDA evaluation for each medicine. Government will be the core party for providing information credentials in the consumers' language to be easily understandable. This credential is imperative to generate e-health literacy, like the crystal-clear certification mark in the UK.

Not only a consumer information source, but an information source for healthcare professionals should also be developed under the support of the government. The source should include updated research and Thai medicinal information with the cooperation of professional associations and pharmaceuticals.

\section{(iii) 'e-Consultation' with healthcare professionals $(C)$}

Consumer needs for digital consultation should not be overlooked. From a professional point of view, healthcare professionals do not desire to compromise their consultation quality by going to a smartphone. However, an economy of health services can be obtained through digital consultation with an acceptable standard of care. Professional associations and government regulatory agencies must cooperate to set the standard of online pharmacies, teleconsultation and drug distribution. The areas of feasible diseases and medicines should be set to be clear-cut remote health services. Responding to consumer needs, the legitimation of digital healthcare services and standardization of official services for consumers prevent the risk of rogue pharmacies and inaccessibility to medical consultation.

This has been especially true during the end of this research, as the spread of COVID19 encourages more demand for teleconsultation or telepharmacy. There is widespread implementation without legal approval. The benefit of digital consultation with online pharmacy outweighs the risk if there is a proper control policy to reinforce the standard of care and prevents criminal pharmacies. The certification of Good Distribution Practices (GDP) and telemedicine provide legitimation of teleconsultation in Thailand.

\section{(iv) 'e-Ethics' Development in pharmaceutical industry (E)}

The government regulatory agencies, professional associations and the pharmaceutical industry in Thailand cooperate to develop standards and ethics in digital marketing so that the pharmaceutical business could focus on providing complete, balanced information, rather than providing information for only commercial benefit. Although multinational pharmaceutical firms hold their own code of conduct, domestic recognition would strengthen local ethics compliance. To promote a positive image of the business itself, an award should be given to the pharmaceutical companies that 
comply with standards and ethics in digital marketing. On the other hand, a penalty should be applied, like blacklisting, for unethical drug business operations such as drug advertisements, off label promotion, hidden advertisements, etc. Future marketing selfregulation by professional associations and the pharmaceutical industry can be conducted in Thailand.

Figure 3: Proposed R-I-C-E model of digital pharmaceutical marketing

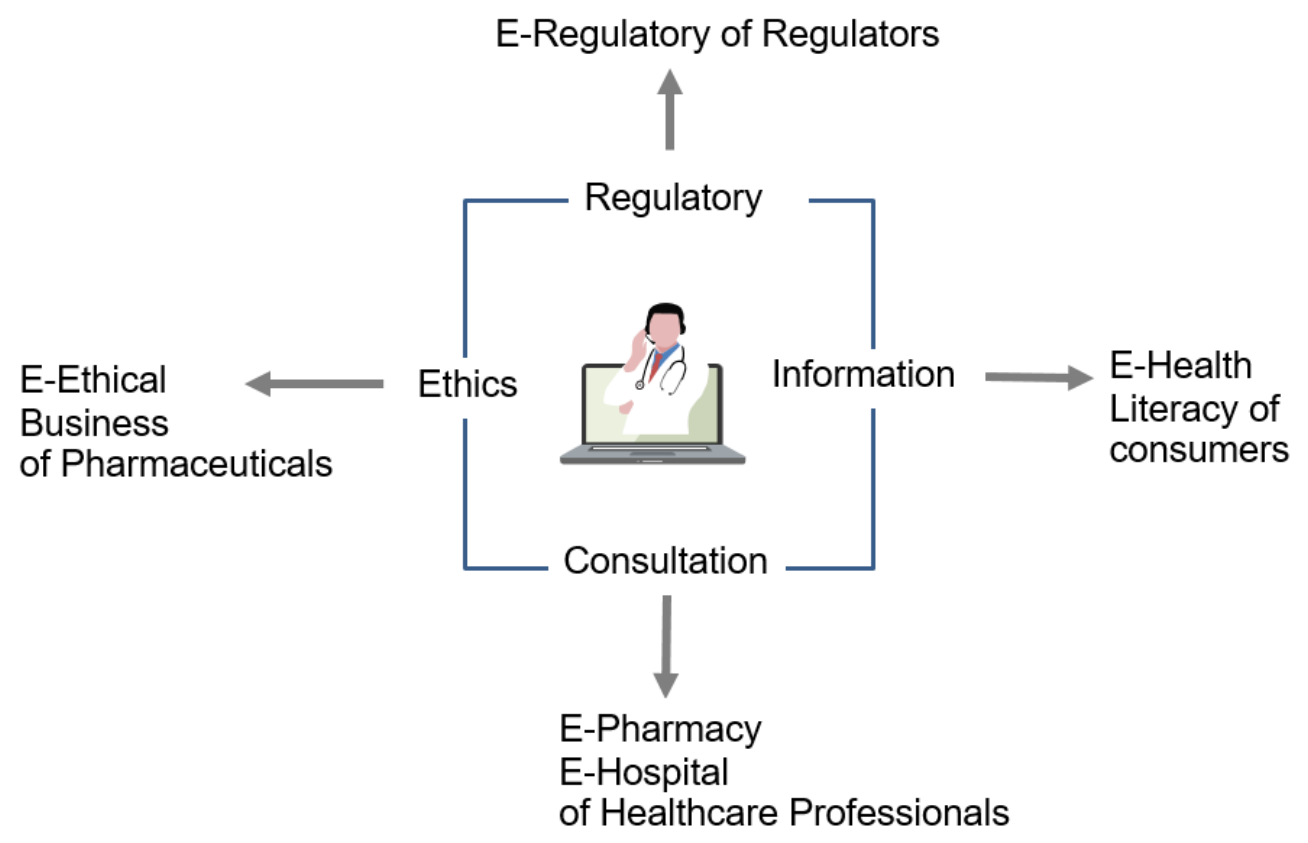

Following prototype development, a test was conducted with the same group of 53 informants. The informants agreed with the acceptability of a prototype ( $\min 4$ and $\max$ 4.56 of 5$)$.

Table 3: Acceptability Tests of Each Prototype

\begin{tabular}{lcc}
\hline \multicolumn{1}{c}{ Solution } & Mean & SD \\
\hline 1.Plaftorm for Regulatory Control (E-Regulatory) & & \\
1.1 Post-marketing monitoring focus & 4.10 & 0.886 \\
1.2 Identification Technology & 4.40 & 0.782 \\
1.3 Communication Technology & 4.00 & 0.948 \\
1.4 Surveillance, prevention and enforcement technology against & 4.34 & 0.772 \\
digital misconduct & & \\
2.Development of drug information sources (E-Information) & 4.38 & 0.780 \\
2.1 Drug information for consumers & 4.22 & 0.887 \\
2.2 Drug information for healthcare professionals & 4.60 & 0.571 \\
3. Digital consultation with healthcare professionals (E-Consultation) & 4.46 & 0.734 \\
3.1 Good distribution practices & & \\
3.2 Online pharmacy standard & 4.56 & 0.577 \\
4. Ethics development in the pharmaceutical industry (E-Ethics) & \\
4.1 Pharmaceutical Ethics &
\end{tabular}


Figure 4: Prototype Test with Research Informants

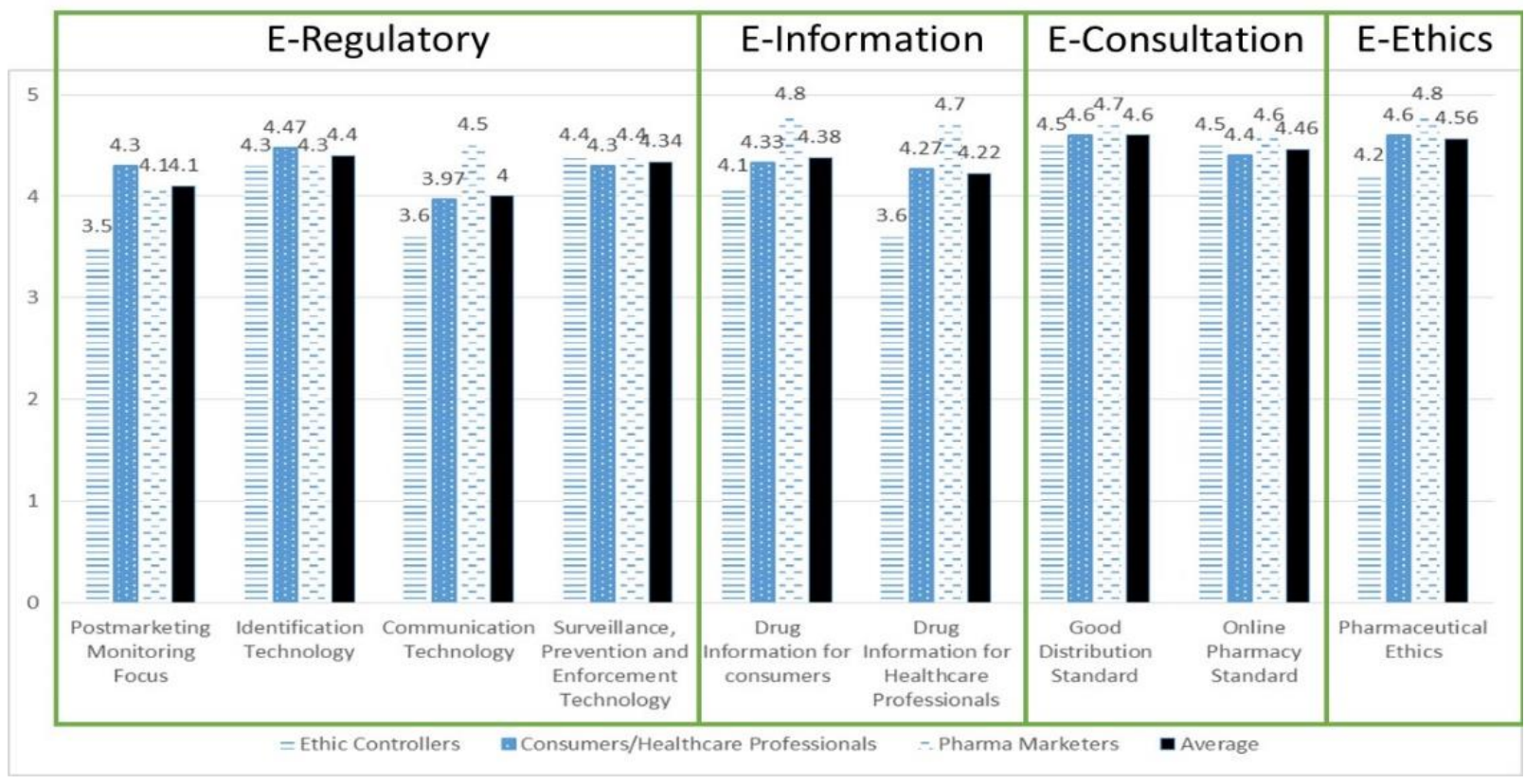

\section{Discussion}

The research challenges derive from the conflict of interest among pharmaceutical companies as their objective is to both maximize profits and ensure that patients receive the most safe, effective, and individualized information and medications at any given time, along with the need of regulatory officials to protect consumers from any persuasion attempts regarding medications. Therefore, we need to find the optimal way to carry out digital marketing. The process is to engineer a balanced solution which benefits all users of digital marketing rather than regulations that favor business advantage. The value of marketing strategies from this research emerges as the humanistic marketing concept, where companies can apply sustainable ways to do business that benefits society as well.

Today, Thai consumers and healthcare providers search for drug information through digital media, in accordance with the results of U.S. surveys (Boruff \& Storie, 2014; Girardi, 2017). Consumers need reliable and easy understandable information, whereas healthcare providers seek out scientific information that is deep and unbiased to solve patient treatment problems. The development of digital information sources is required as an important reference for people (Cheng, So, Fung, Hung \& Lee, 2018). Additionally, digitized consultation with health personnel remains a challenging necessity where health systems may have to provide option to solve these problems of both consumers and professionals. The findings recommend setting up professional teleconsultations with online pharmacies that must be legitimized and standardized similar to the US, Canadian and European markets. Openness of digital health facilities is needed to increase health access in a cost-effective manner. The arguments on qualities of digital consultation remain professional concerns, but the healthcare shortage plus consumer behaviors are key drivers for unavoidable healthcare digitalization. At the end of data collection in this study, following the increase of the coronavirus pandemic globally, UK online pharmacies delivered the necessary safety measures and health information on COVID-19 (Business Matters, 2020). Whereas in 
countries without legitimated online consultation, like Thailand, consumers face the danger of buying falsified drugs from a rogue pharmacy without any healthcare provider consultation.

There is no doubt that consumers in countries with restricted drug advertising like Thailand have access to biased drug information and drug selling without any proper control, similar to unrestricted eDTC in Canada and the USA (Mackey, 2016). The challenge to Thai regulatory agencies is, despite high bar of consumer protection, the pre-approval process is voluntarily, and enforcement is handicapped. Resources do not strictly apply sanctions for non-submission. This limitation has encouraged unethical companies not to ignore regulations and risk unethical marketing for the sake of higher profit. Existing law is also weak on covering unbranded communication. A new way of regulation is recommended for Thailand. It may be the right time to empower ethical organizations to provide reliable information while quickly monitoring and sending alerts for any marketing misconduct on a digital space. Our results propose a partnership using technology as the key to e-regulations to drive digital marketing governance consistent with the previous literature (Mackey \& Liang, 2013). The findings propose to decrease a degree of preapproval process and increase intensive e-monitoring, especially of unbranded information. Thus, pharmaceutical companies that apply ethics toward their digital marketing are more likely to be free from further restrictions and vice versa.

From a managerial point of view, the results recommend that pharmaceutical companies who wish to introduce medicines to consumers and healthcare professionals should provide more accurate, fair and balanced information under government credentialed sources for the benefit of all information users. The pharmaceutical industry should abandon short term financial objectives that risk destroying their image and plead guilty to illegal marketing (De Freitas et al., 2013), such as one of the big settlements from GSK, which was as high as three billion USD, for their off-label promotion.

From a theoretical point of view, our findings recommend that government officials and professional associations hold a primary role in digital pharmaceutical marketing. Medicine is an ethical good, so the expectations of digital marketing should contribute to the overall welfare of everyone. Pharmaceuticals cannot be responsible for digital marketing on their own. As contributed by Agency theory (Eisenhardt, 1989), pharmaceutical companies on their own are not able to be good advocates for societal wellbeing. Firm objectives are to maximize profits by influencing both healthcare professionals and consumers through "provider-directed" and "direct-to consumer" information. Public concerns continue in rising digital spending and the effect has permitted pharmaceutical companies to bypass traditional doctor-patient relationships, thus influencing the treatment decisions of consumers. Pharmaceutical marketers hold an ambiguous role between company effectiveness and ethics. From design thinking, a monitoring technology and award mechanism for ethical informative agents should be developed to maintain ethical operations of pharmaceutical companies consistent with 'monitoring' and 'incentives' to prevent agent fraud as in the agency theory. Additionally, the findings also contribute theoretically to the social or humanistic marketing of products (Borgerson, 2015). Advertising to increase product demand becomes unethical for medicines that determine rational consumption, which is what consumers really need and want. Informative marketing with professional advice 
remains imperative for digital pharmaceutical marketing and other humanistic product marketing like hospital treatment, and educational or charity services. Consumer information that raises quality of life should be qualified and free from the persuasive commercial offerings of business operators.

\section{Conclusions}

Digital pharmaceutical marketing can benefit consumers, healthcare providers and pharmaceutical target audiences by responding to information seeking behaviors. However, the digital marketing free ride by for-profit pharmaceuticals can be curtailed by implementing controls, monitoring, and reinforcement from government agencies to prioritize societal welfare and restrict any opportunistic behaviors practiced by unethical business. This study employed a design thinking process to optimize traditional qualitative research methodologies and proposes the four R-I-C-E domains for the solutions: $\mathrm{R}$ for the e-Regulations of government officials by using technology and partnerships to monitor digital pharmaceutical marketing, I for e-Information sources under government credentials for reliable drugs and easily understandable information, $\mathrm{C}$ for e-Consultation by healthcare professionals to provide convenient and cost-effective platforms for care and $\mathrm{E}$ for the e-Ethics operations of pharmaceuticals by introducing an ethics award and recognition for high ethical pharmaceutical companies.

\section{Limitation and Recommendation for Further Research}

This study is based on one cycle of design thinking. All guidelines, like e-regulatory, teleconsultation, information source, and ethics must develop into a detailed prototype and be tested iteratively until reaching a finished product and launch. Other researchers can use these initial marketing guidelines to develop valid marketing policies. Therefore, further confirmatory research on large samples is recommended to confirm the proposed guidelines, especially in cases of expensive proposed projects, like the monitoring technology being up to date with the realities of digital marketing and information source development.

\section{Implications for Asian Business}

The expenditure on Asian medicines and healthcare is expected to grow mainly from an increasing population of the elderly and the higher prevalence of chronic disease. Pharmaceutical companies invest proportionately more on digital media to gain higher sales in Asia. Drug regulations in Asian developing countries have an extended approach to traditional pharma marketing toward digital marketing and use strict controls on information that might influence consumers and healthcare providers. The study highlights national marketing policies to provide for the proper digital marketing of pharmaceutical products for all stakeholders. Government monitoring technology and social networking are recommended to control digital marketing. Information digital sources should be provided or endorsed by regulatory offices and healthcare professional entities. Here, a framework of the R-I-C-E (e-Regulatory, e-Information, e-Consultation and e-Ethics) model is proposed to balance all the tension and provide solutions for digital marketing practices in the healthcare setting. 
Pharmaceutical companies in the future will develop more connectivity, data analytics and consumer-engaging tools in digital media to reduce the cost of promotion but expand consumer reach to positively impact sales growth. Given the growing magnitude of digital marketing strategies and implementations in healthcare, proper guidelines should be provided to acquire the innovative value of technology without the perceived risks of providing biased information to consumers. Pharmaceuticals as a humanistic business will need to actively work with regulators and healthcare providers to execute a digital marketing path forward.

Importantly, we are all living in the digital era. Digital communication dissolves the borders between individual ASEAN nations with diverse regulations, digitalization and globalization, which demand global or regional policies management rather than many diverse policies. If the proposed guidelines from the study can be further implemented, then pharmaceutical marketing firms who highly adapt to digitalization and aim to behave ethically can be effectively controlled and offer governance on drug communication for the overall welfare of healthcare. The code of ethics should be supported by all ethics controllers. At the same time, the digital population shows an increasing level of e-health digital literacy as mandatory knowledge to protect their drug information-seeking behaviors. Other humanistic industries such as religious, healthcare or education can use a human focus approach like this research to provide innovative solutions for existing problems.

In this study, design thinking is a design-based research methodology that focuses on solving the problem of conflicting interests among multiple stakeholders through a human-centric approach. The design thinking process is well-known for new product development, where it is recommended for policy innovation and healthcare. This study establishes some important initiatives in that design thinking can be leveraged for marketing policies and complex national problems in an Asian context by empathizing relevant stakeholder needs and brainstorming among experts. To solve other challenging problems in Asian regions, such as modern education management, COVID-19 pandemics measures, environmental restoration, etc., design thinking can be implemented as an excellent method on the national level. Given its potential benefits in healthcare marketing policies, other policy-making bodies can be set up in Asian countries to integrate design thinking into their policies and legal processes.

\section{References}

Altman, M., Huang, T. T., \& Breland, J. Y., (2018), "Design thinking in health care", Preventing Chronic Disease, vol. 15, no. 117, pp. 1-13.

Becker, K. D., Park, A. L., Boustani, M. M., \& Chorpita, B. F., (2019), "A pilot study to examine the feasibility and acceptability of a coordinated intervention design to address treatment engagement challenges in school mental health services", Journal of school psychology, vol. 76, no., pp. 78-88.

Borgerson, J. L., (2015), "Humanistic marketing", Consumption Markets \& Culture, vol. 18, no. 2, pp. 195-201. doi:10.1080/10253866.2014.925689

Boruff, J. T., \& Storie, D., (2014), "Mobile devices in medicine: a survey of how medical students, residents, and faculty use smartphones and other mobile devices to find information", Journal of the Medical Library Association : JMLA, vol. 102, no. 1, pp. 22-30. doi:10.3163/1536-5050.102.1.006

Brown, T., (2008), "Design thinking", Harvard business review, vol. 86, no. 6, pp. 84. 
Buchanan, R., (1992), "Wicked problems in design thinking", Design issues, vol. 8, no. 2, pp. $5-21$.

Business Matters. (2020). "Impact of COVID-19 on online pharmacy business. Retrieved 19 August, 2020, from https://www.bmmagazine.co.uk/business/impact-of-covid-19-ononline-pharmacy-business/

Chan, K., (2018), "A design thinking mindset beyond the public health model", World Medical \& Health Policy, vol. 10, no. 1, pp. 111-119.

Cheng, F., So, S., Fung, B., Hung, W., \& Lee, V., (2018), "Online drug information platform for the public in Hong Kong-Review of local drug information use and needs", International journal of medical informatics, vol. 114, no., pp. 27-34.

Chiou, L., \& Tucker, C. E., (2016), " How Do Restrictions on Advertising Affect Consumer Search?", no. June 1. doi: http://dx.doi.org/10.2139/ssrn.1542934

Comscore. (2014), "New Pharma Digital Marketing Benchmarks Show that Online Pharmaceutical Marketing Continues to Drive Brand Awareness, Favorability and Conversions," 2020.

Creswell, J. W., \& Poth, C. N. (2016), Qualitative inquiry and research design: Choosing among five approaches, Sage publications.

Davies, K., (2007), "The information-seeking behaviour of doctors: a review of the evidence", Health Information \& Libraries Journal, vol. 24, no. 2, pp. 78-94.

De Freitas, J., et al. (2013), The ethics of pharmaceutical industry influence in medicine, Israel: UNESCO chair in Bioethics.

Dell'Era, C., Magistretti, S., Cautela, C., Verganti, R., \& Zurlo, F., (2020), "Four kinds of design thinking: From ideating to making, engaging, and criticizing", Creativity and Innovation Management, vol. 29, no. 2, pp. 324-344.

Dell'Era, C., Magistretti, S., \& Verganti, R., (2018), "Exploring collaborative practices between SMEs and designers in the Italian furniture industry", Researching open innovation in SMEs, no., pp. 307-345.

Dworkin, S. L., (2012), "Sample Size Policy for Qualitative Studies Using In-Depth Interviews", Archives of Sexual Behavior, vol. 41, no. 6, pp. 1319-1320. doi:10.1007/s10508-012-0016-6

Eisenhardt, K. M., (1989), "Agency theory: An assessment and review", Academy of management review, vol. 14, no. 1, pp. 57-74.

ETDA. (2019). "Thailand Internet User Behavior 2019. Retrieved June 2, 2020, from https://www.etda.or.th/publishing-detail/thailand-internet-user-behavior-2019-en.html

Ferreira, F. K., Song, E. H., Gomes, H., Garcia, E. B., \& Ferreira, L. M., (2015), "New mindset in scientific method in the health field: Design Thinking", Clinics, vol. 70, no. 12, pp. 770-772.

Fox, S., \& Duggan, M., (2013). "Health Online 2013", Retrieved from https://www.pewresearch.org/internet/2013/01/15/health-online-2013/

Girardi, C., (2017, 6 July). "The Evolving Role of Digital Marketing in Healthcare", Balance.com. Retrieved from https://www.evariant.com/blog/evolving-role-digitalmarketing-healthcare

Goodman, S. N., Schneeweiss, S., \& Baiocchi, M., (2017), "Using design thinking to differentiate useful from misleading evidence in observational research", Jama, vol. 317, no. 7, pp. 705-707.

Hendricks, S., Conrad, N., Douglas, T. S., \& Mutsvangwa, T., (2018), "A modified stakeholder participation assessment framework for design thinking in health innovation", in Healthcare, Elsevier, pp. 191-196.

Holtgräfe, C., \& Zentes, J., (2012), "Multifaceted determinants of online non-prescription drug information seeking and the impact on consumers' use of purchase channels", Health Informatics Journal, vol. 18, no. 2, pp. 95-110.

Homhuan, A., (2013, 15 July). "Thailand to Crack Down on Illegal Online Pharmacies", Retrieved from https://www.tilleke.com/resources/thailand-crack-down-illegal-onlinepharmacies 
Jacobs, W., Amuta, A. O., \& Jeon, K. C., (2017), "Health information seeking in the digital age: An analysis of health information seeking behavior among US adults", Cogent Social Sciences, vol. 3, no. 1, pp. 1302785. doi:10.1080/23311886.2017.1302785

Katoppo, M. L., \& Sudradjat, I., (2015), "Combining Participatory Action Research (PAR) and Design Thinking (DT) as an alternative research method in architecture", ProcediaSocial and Behavioral Sciences, vol. 184, no., pp. 118-125.

Keshavarz, M., \& Maze, R., (2013), "Design and dissensus: framing and staging participation in design research", Design Philosophy Papers, vol. 11, no. 1, pp. 7-29.

Kim, H., (2015), "Trouble spots in online direct-to-consumer prescription drug promotion: a content analysis of FDA warning letters", International journal of health policy and management, vol. 4, no. 12 , pp. 813.

Kumnooy, P., (2020), "Illegal Drug Advertisings and Strategy", Thai Food and Drug Journal, vol. 27, no. 1, pp. 41-52 [in Thai].

Lad, P., Muragundi, P., \& Ligade, V. S., (2017), "Digitalize pharmaceutical marketing: Medical representative perspective", Research Journal of pharmacy and technology, vol. 10, no. 7, pp. 2179-2182.

Lalazaryan, A., \& Zare-Farashbandi, F., (2014), "A review of models and theories of health information seeking behavior", International Journal of Health System and Disaster Management, vol. 2, no. 4, pp. 193.

Leelavanich, D., Adjimatera, N., Broese Van Groenou, L., \& Anantachoti, P., (2020), "Prescription and Non-Prescription Drug Classification Systems Across Countries: Lessons Learned for Thailand", Risk management and healthcare policy, vol. 13, no., pp. 2753-2768. doi:10.2147/RMHP.S281629

Lefebvre, R. C., \& Kotler, P., (2011), "Design thinking, demarketing and behavioral economics: Fostering interdisciplinary growth in social marketing", The Sage handbook of social marketing, no., pp. 80-94.

Limbu, Y. B., McKinley, C., \& Temperini, V., (2019), "A longitudinal examination of FDA warning and untitled letters issued to pharmaceutical companies for violations in drug promotion standards", Journal of Consumer Affairs, vol. 53, no. 1, pp. 3-23.

Lockwood, T. (2009), Design Thinking: Integrating Innovation, Customer Experience, and Brand Value, Simon and Schuster.

Mackey, T. K., (2016), "Digital direct-to-consumer advertising: A perfect storm of rapid evolution and stagnant regulation: comment on" Trouble spots in online direct-toconsumer prescription drug promotion: a content analysis of FDA warning letters"", International journal of health policy and management, vol. 5, no. 4, pp. 271.

Mackey, T. K., \& Liang, B. A., (2013), "Pharmaceutical digital marketing and governance: illicit actors and challenges to global patient safety and public health", Globalization and health, vol. 9, no. 1, pp. 45.

Maimon, P., (2018), "Survey of Drug Selling over Popular Shopping Websites in Thailand", Thai Journal of Pharmacy Practice, vol. 11, no. 2, pp. 368-377.

Malterud, K., Siersma, V. D., \& Guassora, A. D., (2016), "Sample size in qualitative interview studies: guided by information power", Qualitative health research, vol. 26, no. 13, pp. 1753-1760.

McGann, M., Blomkamp, E., \& Lewis, J. M., (2018), "The rise of public sector innovation labs: experiments in design thinking for policy", Policy Sciences, vol. 51, no. 3, pp. 249-267.

Medicine Regulation Division. (n.d.). "Things to know about drug advertising [in Thai]", Retrieved

from https://www.fda.moph.go.th/sites/drug/SitePages/advertisement03.aspx

Memisoglu, M., (2017), "Marketing communications for over-the-counter drugs and nonpharmaceutical products: the professionals' perspective", International Journal of Healthcare Management, no.

Miaskiewicz, T., \& Kozar, K. A., (2011), "Personas and user-centered design: How can personas benefit product design processes?", Design studies, vol. 32, no. 5, pp. 417430. 
Mintrom, M., \& Luetjens, J., (2016), "Design thinking in policymaking processes: Opportunities and challenges", Australian Journal of Public Administration, vol. 75, no. 3, pp. 391-402.

Oyor Digital Library. (2019). "Thai FDA Reveals Surveillance Statistics Examining Illegal Health Products 2020(June 2, 2020). Retrieved December 2, 2020, from https://oryor.com/\%E0\%B8\%AD\%E0\%B8\%A2/detail/media news/1748 (in Thai)

Parekh, D., Kapupara, P., \& Shah, K., (2016), "Digital pharmaceutical marketing: a review", Research Journal of pharmacy and technology, vol. 9, no. 1, pp. 108-112.

Payne, A. F., Storbacka, K., \& Frow, P., (2008), "Managing the co-creation of value", Journal of the academy of marketing science, vol. 36, no. 1, pp. 83-96.

Ratcliffe, M., (2012), "Phenomenology as a Form of Empathy", Inquiry, vol. 55, no. 5, pp. 473495.

Roberts, J. P., Fisher, T. R., Trowbridge, M. J., \& Bent, C., (2016), "A design thinking framework for healthcare management and innovation", Healthcare, vol. 4, no. 1, pp. $11-14$.

Sirikanratana, C., (2016), "Legal Problems Related to Drug and Dietary Supplement. Cosmetics and Medical Supplies Advertisement via Website", Assumption University Law Journal, vol. 7, no. 2, pp. 113-128 (in thai).

So, C., \& Joo, J., (2017), "Does a Persona Improve Creativity?", The Design Journal, vol. 20, no. 4, pp. 459-475. doi:10.1080/14606925.2017.1319672

Tan, S. S.-L., \& Goonawardene, N., (2017), "Internet health information seeking and the patient-physician relationship: a systematic review", Journal of medical Internet research, vol. 19, no. 1, pp. e9.

Thailaws.com. (n.d.). "Drug Act 1967. Retrieved June 2, 2020, from http://thailaws.com/law/t_laws/tlaw0071_1.pdf

Varey, R., \& Pirson, M. (2013), Humanistic marketing, Hampshire: Palgave MacMillan. 